\title{
An Overview of Specific Pathogens in Goat Mastitis
}

\author{
Cristiana Ștefania NOVAC ${ }^{1}$, Sanda ANDREI ${ }^{1^{*}}$, Nicodim Iosif FIȚ $^{2}$ \\ ${ }^{1}$ Department of Preclinical Sciences, Faculty of Veterinary Medicine. University of Agricultural Sciences \\ and Veterinary Medicine Cluj-Napoca, Romania \\ ${ }^{2}$ Department of Clinical and Paraclinical Sciences, Faculty of Veterinary Medicine. University of \\ Agricultural Sciences and Veterinary Medicine Cluj-Napoca, Romania \\ *corresponding author: sandrei@usamvcluj.ro
}

Bulletin UASVM Veterinary Medicine 76(2)/2019

Print ISSN 1843-5270; Electronic ISSN 1843-5378

doi:10.15835/buasvmcn-vm:2019.0025

\begin{abstract}
:
Goat milk ranks fourth in terms of global milk production and lately it has become increasingly popular among consumers. Unfortunately, mastitis is one of the most common diseases that affects dairy goats, with serious economic consequences and food safety matters. The prevalence of clinical mastitis is lower than $5 \%$ and the main aetiological agent is $S$. aureus. On the other hand, the prevalence of subclinical mastitis is between $5-30 \%$, with coagulase negative staphylococci (CNS) representing the most often isolated microorganisms.

The aim of this paper is to highlight the main aspects regarding the aetiology of goat mastitis, as well as the importance of the milk somatic cell count (MSCC) in the diagnosis process. Although the inflammation of the mammary gland in goats is not as frequently diagnosed compared to cow mastitis, there are several aspects worth discussing in order to fully understand the pathogenesis of intramammary infections.
\end{abstract}

Keywords: aetiology, goat, mastitis, milk somatic cell count

\section{Introduction}

Mastitis is defined as the inflammation of the mammary gland. Most often, the inflammatory process occurs as a result of intramammary infections with different pathogenic agents, but also physical, chemical or mechanical injuries can lead to mastitis (Accorsi et al., 2002). Regardless of the species, factors affecting the udder health are considered to be limiting factors in the development of the dairy industry, which lead to major economic consequences resulting from significantly decreased milk production and expensive veterinary services, especially antibiotic treatments (Ajuwape et al., 2005).

Mastitis in small ruminants is considered to be highly important from several points of view. First of all, the economic aspect is the one that prevails, the diseases of the mammary gland resulting in quantitative and qualitative decrease of milk yield, along with the prescription of costly therapeutic protocols. Furthermore, severely affected animals are, most often, slaughtered. It is also worth mentioning the importance of the hygiene and safety criteria of milk and dairy products, with the risk of illness occurring among consumers, due to the consumption of possibly contaminated products. Nevertheless, the legal aspects regarding the microbiological quality of the milk should be implemented and respected accordingly (Olechnowicz and Jaśkowski, 2014).

An important aspect regarding the pathology of mastitis is the concept of microbiota of the mammary gland. In recent years, the 
sterility of healthy mammary tissue has been questioned, being disproved by the results of studies based on the presence of bacterial DNA. Thus, studies conducted on bovine milk concluded that there is an intramammary normal flora in the healthy udder composed of a variety of bacteria. Furthermore, it is stated that mastitis would be, predominantly, a consequence of the dysbiosis of the microbiota rather than a primary infection (Contreras and Rodriguez, 2011; Oikonomou et al., 2012; Rainard, 2017).

To confirm this hypothesis, it has been shown that the microbial flora in milk samples from healthy cows is different from that of cows diagnosed with mastitis. Also, the presence of several bacterial species such as Staphylococcus aureus and Streptococcus uberis in healthy bovine milk samples, with a low number of somatic cells, reinforced the statement according to which bacteria that is normally found on the surface of the skin or intestinal mucosa are also a part of the commensal flora of the mammary gland (Oikonomou et al., 2014).

\section{Epidemiological aspects of goat mastitis}

From a clinical point of view, mastitis is divided in two categories: clinical and subclinical mastitis. Clinical mastitis is defined as the inflammation of the mammary gland in which visible, local and even general symptoms occur, along with significant changes in milk secretion, while subclinical mastitis develops without clinical signs. In this particular case, the diagnosis protocol is based on milk examination. Additionally, clinical mastitis can be divided into three categories according to its evolution: peracute, acute and chronic mastitis. Peracute mastitis has a very rapid evolution and is most often gangrenous or serous. On the other hand, acute mastitis is divided into catarrhal and hemorrhagic mastitis, whilst chronic mastitis is often purulent (Groza et al., 2006).

In small ruminants, the incidence of clinical mastitis is generally less than $5 \%$, whereas subclinical disorders are considered to have an incidence ranging from 5 to 30\% (Bergonier and Berthelot, 2003; Contreras et al., 2003). Among the pathogens that may cause mastitis in sheep and goats, bacteria of the genus Staphylococcus are most commonly isolated, but other agents causing mastitis, such as Streptococcus spp., Enterobacteriaceae, Pseudomonas aeruginosa,
Mannheimia haemolytica, Corynebacterium spp. can be isolated, with a lower prevalence. Cases of mastitis produced by Aspergillus fumigatus, Serratia marcescens or Burkholdelia cepacia are also reported (Kalogridou-Vassiliadou, 1990; Bergonier and Berthelot, 2003; Contreras et al., 2003). Although Streptococcus spp. and Gram-negative bacilli are known to be major intramammary pathogens in cows, they are not very frequently isolated from mammary gland infections in the goat and are more likely associated with poor hygiene and milking conditions. In addition to the before mentioned pathogens, other microorganisms that can cause mastitis in goats, but with a lower frequency, are Arcanobacterium pyogenes, Bacillus spp., Clostridium perfringens, Nocardia asteroides (Contreras et al., 2003).

Furthermore, Mycoplasma spp. represents another pathogenic agent that causes mastitis in small ruminants, being responsible for the evolution of the contagious agalactia syndrome. This disease has a high prevalence in the Mediterranean region, but it has also been reported in other parts of the world (Contreras et al., 2003). Because various symptoms other than mastitis are observed in this disease, different authors do not consider Mycoplasma spp. as an aetiologic agent of intramammary infections. However, the evolution of this syndrome results in reduced milk production and significant increase in MSCC. Due to this fact, some authors consider this pathogen as being one of the most important causes of mastitis in endemic areas, where the incidence of subclinical mastitis is high. In herds where contagious agalactia evolves, large economic losses are reported due to decreased milk production, mortality or slaughter of affected animals (Corrales et al., 2004).

Regarding the evolution of clinical mastitis, Staphylococcus aureus is the main aetiological agent, with the highest prevalence, followed by coagulase-negative staphylococci (CNS), Streptococcus spp., Enterobacteriaceae, Arcanobacterium pyoegenes, Corynebaterium spp., Pasteurellaceae etc. Enzootic or epizootic episodes are mainly due to the presence of $S$. aureus, Streptococcus uberis, S. agalactiae, S. suis or opportunistic pathogens, such as Aspergillus fumigatus, Pseudomonas aeruginosa and less commonly Serratia marcescens or Burkholderia cepacia (Las Heras et al., 2000; Berriatua et al., 2001; Bergonier et al., 2003). 
The persistence of clinical intramammary infections during lactation depends on the size of the herd and technological factors. If left untreated, animals in the acute phase become chronic, with the disease spreading for several months or longer. In the selected goat herds, $18 \%$ of the slaughtered animals undergo mastitis episodes. In both goats and sheep, mammary pathology is one of the main causes of culling, being more frequent in the first 2-3 months of lactation (Malher et al., 2001). According to the study conducted by Sanchez et al. (1999), the incidence of clinical mastitis does not vary with the stage of lactation to the same extent as in cattle. A higher rate of mastitis is observed at the beginning of the milking period and in the first third of lactation.

As mentioned above, subclinical mastitis in goats is most commonly caused by CNS species, with a high prevalence of Staphylococcus caprae and Staphylococcus epidermidis, the latter being associated with the highest SCC, both in sheep and goats. The persistence of subclinical mastitis during lactation varies depending on the pathogen that has caused the infection, but it is generally high. The conditions that evolve subclinically are hardly detectable (Albenzio et al., 2002; Bergonier et al., 2003). In goats, a higher frequency regarding subclinical mastitis is observed at the beginning of lactation, the prevalence increasing along with the parity (Sanchez et al., 1999).

The primary sources of infection are the carrier animals, but also the evolution of nonclinically detectable mastitis. Bacterial persistence in the environment is mainly due to technological errors regarding milking machines and poor hygiene. Furthermore, the high density of flocks and overpopulated shelters cause a decrease in the air quality and an increase in the concentration of the total number of germs, this particular aspect being associated with incorrect ventilation and increased humidity in the shelter (Bergonier et al., 2003).

\section{The main aetiological agents of caprine mastitis \\ a. Staphylococcus spp.}

The genus Staphylococcus includes different species of ubiquitary present microorganisms, found on the epithelial surfaces and skin, both in humans and animals. They are resistant to drought, osmotic shock and temperature variations. When the balance of the commensal microbial flora is disturbed and the defense mechanisms of the body are overturned, staphylococci multiply, causing local or even general infections (Andrei and Groza, 2010). Morphologically speaking, these microorganisms are round-shaped (cocci) that stain strongly gram-positive and form grape-like clusters. The number of species is constantly increasing, over 40 species and more than 20 subspecies being described, the main differentiating factor being the production of coagulase. Coagulase is an enzyme responsible for prothrombin activation, promoting plasma coagulation. Thus, Staphylococcus species are divided into coagulase-negative staphylococci (CNS), which do not produce coagulase and coagulase-positive staphylococci (CPS), this aspect being an indicator of pathogenicity (McVey et al., 2013; Becker et al., 2014).

By far the most frequently isolated pathogen from cases of goat mastitis is Staphylococcus spp. (Bergonier et al., 2003; Marogna et al., 2012; Rola et al., 2015; Pirzada et al., 2016). Intramammary infections caused by these pathogens are of particular importance, as these microorganisms are responsible for both the onset of clinical (gangrenous) and subclinical mastitis. Staphylococcus aureus is a CPS, characterised by a very high pathogenicity, very frequently involved in the aetiology of mastitis. It is shown that between 4 and $18 \%$ of bacterial intramammary infections are caused by this pathogen (Bergonier et al., 2003; Contreras et al., 2007; Dore et al., 2016).

In terms of pathogenicity, $S$. aureus produces a series of toxins responsible for causing food poisoning among the human population consuming contaminated milk, even pasteurized, due to the presence of thermostable enterotoxins (Contreras et al., 2007). Moreover, besides these enterotoxins, a number of virulence factors, such as leukotoxins, are also encountered.

These elements have the ability to destroy monocytes and polymorphonuclears (PMN) of the host. In a study conducted by Rainard et al., 2003, it was demonstrated that the $S$. aureus strains isolated from goats and sheep with mastitis have a more pronounced leukotoxic activity on bovine polymorphonuclear cells than those isolated from large ruminants. The same study showed that PMN from small ruminants are more resistant to 
the action of these toxins in comparison to PMN from cattle.

Another important issue is the isolation of methicillin-resistant Staphylococcus aureus (MRSA) strains from goat mastitis. These strains are mostly responsible for nosocomial infections worldwide and their prevalence has increased considerably in recent years. The resistance to methicillin is mediated by the mecA gene, which encodes penicillin-binding protein $2 \mathrm{a}$, making these strains resistant to methicillin or other $\beta$-lactam antibiotic. Such cases have been reported in investigations conducted by Stastkova et al. (2009), Aras et al. (2012), Caruso et al. (2016).

Coagulase-negative staphylococci (CNS) represent the category with the highest prevalence which causes mastitis in ruminants (Contreras et al., 2003; Contreras and Rodriguez, 2011; Silanikove et al., 2014; Gelasakis et al., 2016). Although they are considered to be less pathogenic than $S$. aureus, CNS produce subclinical mastitis, with an increase of MSCC. The prevalence of SCN producing these disorders is $60 \%$ to $80 \%$ in goats and $45-48 \%$ in sheep (Olechnowicz and Jaśkowski, 2014; Persson et al., 2015). The most commonly isolated SCN species from cases of subclinical mastitis in goats are: Staphylococcus epidermidis, S. caprae, S. simulans, S. chromogenes, S. xylosus (Bergonier et al., 2003; Dore et al., 2016) .

Some authors have pointed out that in goats losses that occur due to subclinical infections are limited and that the SCC cannot be used to assess the severity of the infection. However, subclinical mastitis are known to significantly increase the MSCC (McDougall et al., 2002). Intramammary infections with CNS do not have such a pronounced effect on SCC compared to Staphylococcus aureus, thus CNS can be considered minor pathogens in goats (Koop et al., 2010; Koop et al., 2012).

\section{b. Streptococcus spp.}

Streptococci are gram positive, catalasenegative cocci, that tend to form chains of variable lengths or pairs, being characterized by a pronounced ecological, serological and genetic diversity. They are ubiquitous, commensal germs of the upper respiratory and genital tract (McVey et al., 2013). These microorganisms require optimal conditions for growth, with the addition of blood or serum in the culture medium. The pathogenic strains are capsulated and form mucoid colonies (Quinn et al., 2011).

Despite the fact that bacteria of the genus Streptococcus are of major importance regarding the pathology of mastitis in bovine, they do not have a high prevalence in goats. Therefore, streptococcal mastitis account for $5-10 \%$ of the total clinical mastitis cases reported in this species. In general, streptococci are responsible for the onset of clinical infections. In contrast to sheep, where Streptococcus agalactiae is the major pathogen involved in mastitis, studies conducted on goats have shown the absence of this species, showing that the poor hygiene is the main factor that leads to mastitis (Contreras et al., 2003).

Streptococcus equi subsp. zooepidemicus has been isolated from mastitis cases in goats and sheep, as reported by Mallikeswaran and Padmanaban (1991) and Las Heras et al. (2000).

Streptococci produce virulence factors that include enzymes and exotoxins, such as streptolysins (hemolysins), hyaluronidase, streptokinases and proteases, but the polysaccharide capsule is the main virulence factor. Moreover, they produce a series of surface proteins, called adhesins, that bind to the host cell's extracellular matrix proteins, making the microorganisms resistant to phagocytosis. Generally speaking, pathogenic streptococci are susceptible to penicillins, cephalosporins, macrolides, chloramphenicol and sulfamides and are often resistant to aminoglycosides, fluoroquinolones and tetracyclines (McVey et al., 2013).

\section{c. Gram-negative bacteria}

Escherichia coli is a gram-negative bacteria of the genus Escherichia, found in the digestive tract in both mammals and birds, producing local or systemic infections. From the large intestine, these bacteria are eliminated in the environment, thus polluting the soil, water, litter and shelters (Andrei and Groza, 2010). Morphologically speaking, E. coli is a rod-shaped bacterium, which possesses flagella, therefore is motile (McVey et al., 2013).

Colibacillary mastitis in goats are less frequently diagnosed compared to those produced by gram-positive bacteria, this condition being characterized by the presence of both local and general symptoms. Thus, the affected mammary gland is edematous, congested and sensitive to palpation. These symptoms may also be 
accompanied by digestive (diarrhea) and nervous disorders (paraplegia), fever or muscle tremors. At milking, the presence of a serous, yellowish pink secretion can be observed (Groza et al., 2006).

The members of the genus Pseudomonas are involved in the aetiology of goat mastitis, but have a significanlty lower prevalence compared to other bacterial species, being considered opportunistic agents. In general, mastitis caused by Pseudomonas spp. is due to poor milking hygiene, poor maintenance conditions and presence of contaminated water. In addition to this, these conditions may also be a consequence of inappropriate intramammary treatments. Such cases have been mainly reported in sheep flocks (Bergonier et al., 2003; Contreras et al., 2003). Although the genus Pseudomonas comprises more than 200 species and subspecies, most diseases in the veterinary sphere are caused by Pseudomonas aeruginosa. This species is of great importance in internal medicine, because most strains are resistant to commonly used antibiotics, so the infection is difficult to cure (Quinn et al., 2011; McVey et al., 2013).

\section{d. Mycoplasma spp.}

In goats, clinical mastitis caused by mycoplasmas has a high prevalence in some areas, causing much greater economic damage compared to mastitis produced by other pathogens. The contagious agalaxia of small ruminants is endemic in the Mediterranean basin, but is also reported in other regions of the world. The main consequence of the disease is the dramatic decrease in milk yield, which in some cases may be irreversible. Other clinical signs, such as keratoconjunctivitis, arthritis, pneumonia or abortion, may also occur (Contreras et al., 2003).

These microorganisms are frequently found on the mucous membranes of the respiratory and urogenital tracts. In sheep, mastitis is mainly caused by Mycoplasma agalactiae, but in goats other species such as M. mycoides subsp. capri, $M$. capricolum subsp. capricolum, M. putrefaciens are frequently involved in the aetiology of mastitis. In addition to the etiological complexity underlying these infections, a major disadvantage regarding this disease is the poor efficiency of the control and prevention methods (Contreras et al., 2003; Amores et al., 2012; Kumar et al., 2013).
Unlike other pathogens, mycoplasmas are not thought to produce specific toxins, but the production of hydrogen peroxide can induce toxic effects on the cells to the surface on which they adhere. Furthermore, some pathogenic species have certain surface proteins, which facilitate the attachment to cells. These proteins have a pronounced variability, which increases the pathogenicity of these microorganisms (Quinn et al., 2011).

\section{e. Other pathogens}

In addition to the bacterial genera described above, which are frequently isolated from mastitis cases in goats, there are other microorganisms that can cause intramammary infections, but with a lower prevalence. Therefore, grampositive microorganisms include bacteria of the genus Arcanobacterium, especially the species Arcanobacterium pyogenes, formerly known as Actinomyces pyogenes or Corynebacterium pyogenes. These bacteria produce, in most cases, clinical mastitis characterized by a significant decrease in milk production, which is sometimes irreversible (Contreras et al., 2003).

Corynebacterium spp. represents another category of microorganisms that produce subclinical infections among goats, but are considered to be minor pathogens. Other microorganisms, such as Nocardia spp., Bacillus spp. and Clostridium perfringens have also been isolated from goat mastitis, but in sporadic cases (KalogridouVassiliadou, 1991; Contreras et al., 2003).

\section{Aspects regarding diagnostic methods}

The diagnosis of clinical mastitis is based on the examination of the mammary gland, which involves the inspection and palpation of breast tissue, milking, mammary biopsy or other complementary tests (ultrasound, endoscopy), as well as laboratory examinations of milk. On the other hand, subclinical mastitis is detected by milk testing. Thus, the following tests can be used: boiling milk test, pH determination, California Mastitis Test (CMT), reductase and catalase test, determining the electrical conductivity of milk and MSCC (Andrei and Groza, 2010).

The gold standard method used in the diagnosis of mastitis in ruminant species is bacterial culture. For economic, but also practical reasons, a single milk sample is used to diagnose the infection, 
but in order to establish a correct diagnosis, it is necessary to isolate the microorganisms from samples collected consecutively, before and after milking. Due to the fact that the specificity of these tests has been shown to be higher for samples collected after milking, it is highly recommended that the latter should be used for diagnosis (Sanchez et al., 2004; Contreras et al., 2007).

The most important differences between goats and sheep regarding the diagnosis of mastitis are related to the MSCC. These differences relate mainly to the fact that MSCC is normally high in the healthy goats, due to the significant apocrine component of the mammary tissue, but also due to a large number of non-infectious factors leading to this increase in MSCC compared to the sheep. Therefore, in goats, several factors such as treatments, vaccinations, dietary modifications or stress have been found to increase MSCC (Paape et al., 2001; Bergonier et al., 2003). Because MCSS is an indicator of milk quality, it is important that its determination is as accurate as possible. Moreover, in goats, MCSS is not always a suitable indicator of mammary gland health, because a large number of cytoplasmic particles from the apical portion of the secretory cells are found in the milk of this species. Although most of these particles are anucleated, there is a possibility that some of them will contain fragments of the nucleus, leading to the increase of the cell count. The cytoplasmic particles are similar in size to the milk somatic cells, their concentration in the goat species being $150 \times 10^{3} / \mathrm{ml}$ (Paape et al., 2001). If the mammary gland health in cattle is confirmed by MSCC up to 100,000 cells $/ \mathrm{ml}$, in the goat that number can vary between 200,000 cells/ $\mathrm{ml}$ and several million cells/ml (Stuhr and Aulrich, 2010). Furthermore, in goats, neutrophils represent the main cell type of milk somatic cells (aproximately 80\%), unlike cows or sheep, where macrophages are found in a greater percentage. Because neutrophils represent the first line of defense against infections, this fact could explain why goats are more resistant to mastitis than other animal species (Souza et al., 2012).

Persson and Olofsson (2011) proposed a threshold of $345 \times 10^{3}$ cells $\mathrm{mL}^{-1}$ in order to differentiate between infected and healthy glands in goats, but the stage of lactation and parity should be taken into account when it comes to the interpretation of the MSCC.
It is well known that the increase in of MSCC is related to the pathogenicity of the agent that is involved in the aetiology of mastitis. Generally speaking, both the major and minor pathogens described above lead to an increase of MSCC, but in a study conducted by Bagnicka et al. (2011) bacterial pathogens have been isolated from milk samples with a low somatic cell count $\left(1 \times 10^{6} / \mathrm{ml}\right)$.

Another method used for detecting subclinical mastitis is measuring the electrical conductivity of milk. In case of an intramammary infection, changes in the permeability of mammary tissue occur, thus increasing the concentration of $\mathrm{Na}+$ and Cl- in milk. This parameter is used to monitor the health of the mammary gland in cows, being less commonly used in small ruminants (Stuhr and Aulrich, 2010). Also, determining the enzymatic activity can be considered as an adjuvant in establishing a diagnosis. Thus, an enzyme present in large quantities during inflammatory processes is $\beta$-glucuronidase, with correlations being established between the concentration of this enzyme, the increased number of somatic cells and the presence of pathogens. According to Stuhr et al. (2013), $\beta$-glucuronidase activity in goats is not influenced by the stage of lactation, therefore this parameter could represent a better indicator for the detection of mastitis in dairy goats. In the same study mentioned above, non-infected halves showed much lower values in $\beta$-glucuronidase activity in comparison to bacteriologically positive milk samples.

Other milk enzymes that can be used are lactate dehydrogenase, alkaline phosphatase, aspartate-aminotransferase, but also catalase, lactoperoxidase and xanthine oxidase. Like glucuronidase, the concentration of lactoperoxidase in goat milk increases when MSCC also increases, which is also common in women and cattle (Stuhr and Aulrich, 2010; Stuhr et al., 2013).

\section{Conclusion}

The inflammation of the mammary gland in goats is divided into clinical and subclinical disorders, with clinical mastitis having a lower prevalence, below $5 \%$, while subclinical ones have a much higher prevalence. The most frequently isolated pathogen from cases of clinical mastitis is Staphylococcus aureus, and in the subclinical mastitis the highest prevalence is recorded by CNS, other agents being considered minor pathogens, 
except for Mycoplasma spp. The latter causes significant economic damages in the regions where contagious agalactia syndrome evolves (Contreras et al., 2003; Contreras et al., 2007).

The diagnosis of clinical mastitis involves the examination of the mammary gland, whereas subclinical mastitis, without visible symptoms, requires complementary examinations of the milk secretion, in order to establish a correct diagnosis. Therefore, tests that are commonly used for cow milkcanalso be used for the goatmilk, but with some limitations. The determination of the MSCC is not relevant, because the goats shed physiologically a greater number of such cells in the milk secretion, due to the significant apocrine component of the mammary gland and the numerous noninfectious factors that can increase this parameter. Therefore, several indicators should be taken into account when establishing a correct diagnosis for an intramammary infection in goats, as the MSCC does not stand alone for a positive diagnosis. The electrical conductivity, $\mathrm{pH}$, and dosage of certain enzymes may be helpful in establishing a diagnosis (Stuhr et al., 2013). However, the gold standard method for the diagnosis of bacterial mastitis remains the microbiological examination. Within the bacteriological exam, it is also recommended to test the susceptibility to antibiotics, in order to establish an adequate therapeutic protocol and avoid the antibiotic resistance phenomenon.

Acknowledgments. This research project was supported by research grant no. 37PFE/06.11.2018.

\section{References}

1. Accorsi PA, Paccioni B, Pezzi C (2002). Role of prolactine growth hormone and insuline like growth factor in mammary gland involution. J. Dairy Sci., 85:507-513.

2. Ajuwape ATP, Roberts AA, Solarin 00, Adetosoye AI (2005). Bacteriological and haematological studies of clinical mastitis in goats in Ibadan, OYO State, Nigeria. Small Rumin. Res., 60:307-310.

3. Albenzio M, Taibi L, Muscio A, Sevi A (2002). Prevalence and etiology of subclinical mastitis in intensively managed flocks and related changes in the yield and quality of ewe milk. Small Rumin. Res., 43:219-226.

4. Amores J, Sánchez A, Gómez-Martín A, Corrales JC, Contreras A, Dela Fe C (2012). Surveillance of Mycoplasma agalactiae and Mycoplasma mycoides subsp. capri in dairy goat herds. Small Rumin. Res., 102:89- 93.

5. Andrei S, Groza IS (2010). Fiziologia si patologia glandei mamare la vacă, Editura AcademicPres, Cluj-Napoca.
6. Aras Z, Aydin I, Kav K (2012). Isolation of methicillinresistant Staphylococcus aureus from caprine mastitis cases. Small Rumin. Res., 102:68-73.

7. Bagnicka E, Winnicka A, Józwika A, Rzewuska M, Strzałkowska N, Kosciuczuk E, Prusak B, Kaba J, Horbanczuka J, Krzyzewski J (2011). Relationship between somatic cell count and bacterial pathogens in goat milk. Small Rumin. Res., 100:72- 77.

8. Becker K, Heilmann C, Peters G (2014). CoagulaseNegative Staphylococci. Clin. Microbiol. Rev., 27(4):870.

9. Bergonier D, Berthelot X (2003). New advances in epizootiology and control of ewe mastitis. Livestock Production Science, 79:1-16.

10. Bergonier D, De Crémoux R, Rupp R, Lagriffoul G, Berthelot X (2003). Mastitis of dairy small ruminants. Vet. Res., 34:689-716.

11. Berriatua E, Ziluaga I, Virto CM, Uribarren P, Juste R, Laevens S, Vandamme P, Govan JRW (2001). Outbreak of subclinical mastitis in a flock of dairy sheep associated with Burkholderia cepacia complex infection. J. Clin. Microbiol., 39:990-994.

12. Caruso ML, Latorre G, Santagada R, Fraccalvieri A, Miccolupo R, Sottili L, Palazzo A, Parisi,(2016). MethicillinResistant Staphylococcus aureus (MRSA) in sheep and goat bulk tank milk from Southern Italy. Small Rumin. Res. 135: 26-31.

13. Contreras A, C. Luengo A, Sanchez J, Corrales C (2003). The role of intramammary pathogens in dairy goats. Livestock Production Science, 79:273-283.

14. Contreras A, Sierra D, Sanchez A. Corrales JC, Marco JC, Paape MJ, Gonzalo C (2007). Mastitis in small ruminants. Small Rumin. Res., 68:145-153.

15. Contreras GA, Rodríguez JM (2011). Mastitis: Comparative Etiology and Epidemiology. J. Mammary Gland Biol. Neoplasia, 16:339-356.

16. Corrales JC, Sanchez A, Luengo C, Poveda JB, Contreras A (2004). Effect of Clinical Contagious Agalactia on the Bulk Tank Milk Somatic Cell Count in Murciano-Granadina Goat Herds. J. Dairy Sci., 87:3165-3171.

17. Dore S, Liciard M, Amatiste S, Bergagnac S, Bolzoni G, Caligiuri V, Cerronee A, Farinaf G, Montagna CO, Saletti MA, Scatassai ML, Sotgiu G, Cannas EA (2016). Survey on small ruminant bacterial mastitis in Italy, 2013-2014. Small Rumin. Res., 141: 91-93.

18. Gelasakis AI, Angelidis AS, Giannakou R, Filioussis G, Kalamaki MS, Arsenos G (2016). Bacterial subclinical mastitis and its effect on milk yield in low-input dairy goat herds. J. Dairy Sci., 99:1-11.

19. Groza IS, Bogdan L, Cătană R, Cenariu M, Ciupe S, Morar I, Ciupercescu D, Muntean M, Pop A, Stegeran B (2006). Ginecologie, Andrologie și Obstetrică Veterinară Compendiu. Ed. Academiei Române, București

20. Koop G, De Vliegher S, De Visscher A, Supré K, Haesebrouck F, Nielen M, van Werven T (2012). Differences between coagulase-negative Staphylococcus species in persistence and in effect on somatic cell count and milk yield in dairy goats. J. Dairy Sci., 95:9 
21. Koop G, van Werven T, Schuiling HJ, Nielen M (2010). The effect of subclinical mastitis on milk yield in dairy goats. J. Dairy Sci., 93 :5809-5817 doi: 10.3168/jds.2010-3544

22. Kumar V, Rana R, Mehra S and Kumar Rout P (2013). Isolation and Characterization of Mycoplasma mycoides subspecies capri from Milk of Natural Goat Mastitis Cases. Hindawi Publishing Corporation ISRN Veterinary Science Volume, Article ID 593029

23. Las Heras A, Dominguez L, Lopez I, Paya MJ, Pena L, Mazzucchelli F, Garcia LA, Fernandez Garayzabal JF (2000). Intramammary Aspergillus fumigatus infection in dairy ewes associated with antibiotic dry therapy. Vet. Rec., 147:578-580.

24. Malher X, Seegers H, Beaudeau F (2001). Culling and mortality in large dairy goat herds managed under intensive conditions in western France. Livestock Production Science, 71: 75-86.

25. Mallikeswaran K, Padmanaban VD (1991). Microbial flora of milk of goats affected with clinical mastitis. Indian Vet. J,. 68:152-154.

26. Marogna G, Pilo C, Vidili A, Tola S, Schianchi G, Leori SG (2012). Comparison of clinical findings, microbiological results, and farming parameters in goat herds affected by recurrent infectious mastitis. Small Rumin. Res., 102:7483.

27. McDougall S, Pankey W, Delaney C, Barlowb J, Murdough PA, Scruton D (2002). Prevalence and incidence of subclinical mastitis in goats and dairy ewes in Vermont, USA. Small Ruminant Research, 46:115-121.

28. McVey DS, Kennedy M, Chengappa MM (2013). Veterinary Microbiology, Third Edition, John Wiley \& Sons, Inc.

29. Oikonomou G, Machado VS, Santisteban C, Schukken YH, Bicalho RC (2012). Microbial Diversity of Bovine Mastitic Milk as Described by Pyrosequencing of Metagenomic 16s DNA. PLoS ONE, 7(10): e47671. doi:10.1371/journal. pone. 0047671 .

30. Oikonomou G, Bicalho ML, Meira E, Rossi RE, Foditsch C, et al. (2014) Microbiota of Cow's Milk; Distinguishing Healthy, Sub-Clinically and Clinically Diseased Quarters. PLoS ONE 9(1): e85904. doi:10.1371/journal. pone. 0085904.

31. Olechnowicz J, Jaśkowski JM (2014). Mastitis in small ruminants. Medycyna weterynaryjna, 70(2).

32. Paape MJ, Poutrel B, Contreras A, Marco JC, Capuco AV (2001). Milk Somatic Cells and Lactation in Small Ruminants. J. Dairy Sci., 84(E. Suppl.):E237-E244.

33. Persson Y, Järnberg $\AA$, Humblot P, Nymana AK, Waller KP (2015). Associations between Staphylococcus aureus intramammary infections and somatic cell counts in dairy goat herds. Small Rumin. Res., 133:62-66.
34. Persson Y, Olofsson I (2011). Direct and indirect measurement of somatic cell count as indicator of intramammary infection in dairy goats. Acta Vet. Scand., $53,15$.

35. Pirzada M, Malhi KK, Kamboh AA, Rind R, Abro SH, Lakho SA, Bhutto KR, Huda N (2016). Prevalence of subclinical mastitis in dairy goats caused by bacterial species. J. Anim. Health Prod., 4(2): 55-59.

36. Quinn PJ, Markey BK, Leonard FC, FitzPatrick ES, Fanning S (2011). Veterinary Microbiology and Microbial Disease, Second Edition., Blackwell Publishing Ltd.

37. Rainard P, Corrales JC, Barrio MB, Cochard T, Poutrel B (2003). Leucotoxic activities of Staphylococcus aureus strains isolated from cows, ewes, and goats with mastitis: importance of LukM/LukF'-PV leukotoxin. Clin. Diagn. Lab Immunol., 10:272-277. DOI: 10.1128/CDLI.10.2.272277.2003

38. Rainard P (2017). Mammary microbiota of dairy ruminants: fact or fction?. Vet. Res., 48:25 DOI 10.1186/ s13567-017-0429-2.

39. Rola JG, Sosnowski M, Ostrowska M, Osek J (2015). Prevalence and antimicrobial resistance of coagulasepositive staphylococci isolated from raw goat milk. Small Rumin. Res., 123:124-128.

40. Sanchez A, Contreras A, Corrales JC (1999). Parity as a risk factor for caprine subclinical intramammary infection. Small Rumin. Res., 31:197-201.

41. Sanchez A, Contreras A, Corrales JC, Muñoz P (2004). Influence of sampling time on bacteriological diagnosis of goat intramammary infection. Veterinary Microbiology, 98: 329-332.

42. Silanikove N, Merin U, Leitner G (2014). On effects of subclinical mastitis and stage of lactation on milk quality in goats. Small Rumin. Res., 122:76-82.

43. Souza FN, Blagitz MG, Penna CF, Della Libera AM, Heinemann MB, Cerqueira MM (2012). Somatic cell count in small ruminants: Friend or foe?, Small Rumin. Res., 107: 65-75.

44. Stastkova Z, Karpiskova S, Karpiskova R(2009). Occurrence of methicillin-resistant strains of Staphylococcus aureus at a goat breeding farm. Veterinarni Medicina, 54(9): 419-426.

45. Stuhr T, Aulrich K (2010). Intramammary infections in dairy goats: recent knowledge and indicators for detection of subclinical mastitis. Agriculture and Forestry Research, 4 (60):267-280.

46. Stuhr T, Aulrich K, Bartha K, Knappstein K, Larsen T (2013). Influence of udder infection status on milk enzyme activities and somatic cell count throughout early lactation in goats. Small Rumin. Res., 111:139-146. 